\title{
BAGAIMANA MENJADI GENERASI MILENIAL YANG KREATIF DAN MANDIRI DI SMK NEGERI 2 TANGERANG SELATAN
}

\author{
${ }^{1}$ Derizka Inva Jaswita, ${ }^{2}$ Hailidia Maharani, ${ }^{3}$ Rahmayanti Tumanggor, \\ ${ }^{4}$ Lia Asmalah, ${ }^{5}$ Agus Sulaiman \\ Dosen Fakultas Ekonomi Universitas Pamulang \\ Email : $\underline{1}$ dosen02014@unpam.ac.id
}

\begin{abstract}
ABSTRAK
Seluruh kehidupan manusia pada hakikatnya bergelut dalam dimensi waktu. Manusia tidak hanya bergerak dalam lingkungan, tetapi juga saling berinteraksi dalam kehidupan sosial yang melibatkan emosi, etika, pendidikan, dll. karena manusia berada dalam siklus waktu, maka setiap aktivitasnya bermula dalam orientasi berhubungan dengan orang lain.

Siswa adalah bagian dari masyarakat, mereka tidak bisa menghindarkan diri mereka dari masalah interaksi dengan orang lain. Siswa harus dikondisikan untuk mempunyai jiwa mandiri dan diarahkan untuk kreatif dalam kegiatan belajar mengajar oleh karena itu diharapkan para siwa untuk bisa mempersiapkan diri menghadapi perubahan- perubahan di era digital dengan memaksimalkan kegiatankegiatan pelatihan sebagai upaya siap menghadapi perubahan- perubahan di era modern.

Salah satu kegiatan yang dapat menopang adanya kemampuan para siswa dalam mengembangkan diri dan meningkatlkan kreatifitas mereka adalah dengan adanya motivasi dan membuka wawasan yang lebih luas melalui sinergitas antara para pendidik di lingkungan perguruan tinggi dengan berbagi ilmu dan pengetahuan mengenai kesiapan secara mental dan intelektual dalam menghadapi berbagai masalah dan tantangan dalam era globalisasi dan digital saat ini.

Maka dengan adanya kegiatan ini diharapkam dapat memberikan manfaat dalam mengarahkan para siswa SMK Negeri 2 Tangerang Selatan sebagai bagian dari generasi milenial, selain untuk menambah wawasan mereka agar menjadi generasi milenial yang sesuai dengan cita-cita sebagai penerus bangsa di masa depan, juga membantu mereka menemukan solusi terbaik untuk bagaimana dapat menjadi generasi milenial yang kreatif, mandiri dan bermanfaat bagi orang banyak.
\end{abstract}

\section{Kata Kunci: Generasi Milenial, Kreatif, Mandiri, Siswa}

\section{PENDAHULUAN}

Seluruh kehidupan manusia pada hakikatnya bergelut dalam dimensi waktu.Manusia tidak hanya bergerak dalam lingkungan, tetapi juga saling berinteraksi dalam kehidupan sosial yang melibatkan emosi, etika, pendidikan, dll.karena manusia berada dalam siklus waktu, maka setiap aktivitasnya bermula dalam orientasi berhubungan dengan orang lain.

Siswa adalah manusia, mereka tidak bisa menghindarkan diri mereka dari 
masalah interaksi dengan orang lain. Siswa harus dikondisikan untuk mempunyai jiwa mandiri dan diarahkan untuk kreatif dalam kegiatan belajar mengajar oleh karena itu diharapkan siswa- siwa untuk bisa mempersiapkan diri menghadapi perubahan- perubahan di era digital dengan memaksimalkan kegiatan- kegiatan pelatihan sebagai upaya siap menghadapi perubahan- perubahan di era modern.

Bagi siswa pelatihan mengelola kreatifitas dan kemandirian harus dikembangkan dan diterapkan dalam kehidupan sehari-hari, sehingga kata-kata sumbang yang dilontarkan pelajar pada umumnya, seperti kekurangan keterampilan dan kurangnya kreatifitas, dapat di minimalisir.

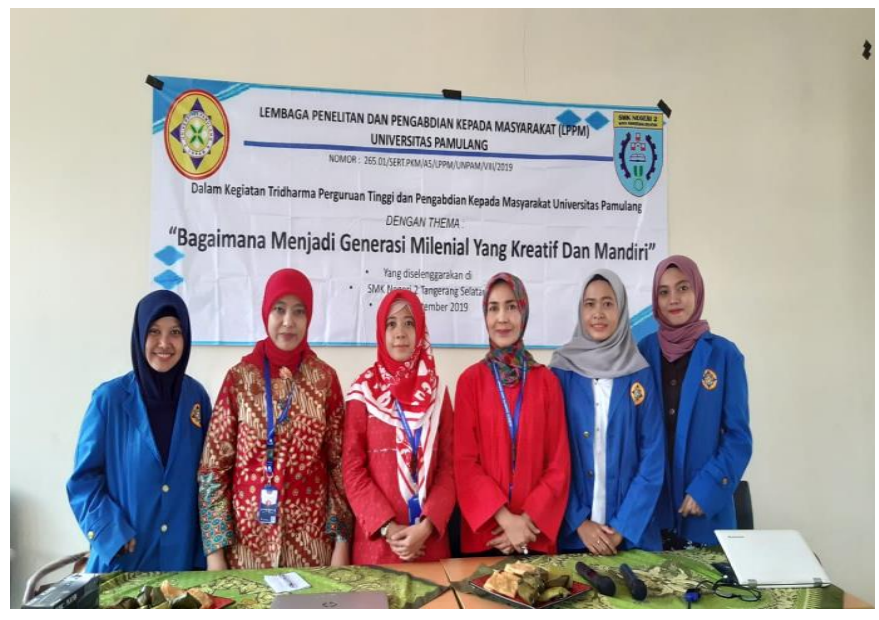

Gambar 1. Persiapan Kegiatan Sosialisasi PKM

\section{METODE PELAKSANAAN KEGIATAN}

Metode kegiatan yang digunakan adalah dengab memberikan pelatihan ke SMKN 2 Tangsel, Jl. Mushola Nurul Huda Pamulang Tangerang Selatan.

\section{HASIL DAN PEMBAHASAN}

Membangun Usaha Generasi Milenial. Banyak sekali manfaat yang bisa kamu dapatkan ketika menggunakan media social. Mulai dari lahan bisnis hingga menjadi tempat bersosialisasi. Bagi generasi milenial, media sosial ini menjadi salah satu yang wajib mereka miliki. Membangun Bisnis, Setiap bisnis saat ini harus memiliki satu atau empat halaman di media sosial, yang di mana untuk melayani semua berbagai jenis pembeli.Hal ini sangat membantu kamudalam membangun bisnis, tetapi juga dapat merusak reputasi, jika kamu melakukan beberapa kesalahan.

Temukan Tempat yang Pas, Kita semua adalah orang yang berbeda minat, hobi, pandangan politik, agama, dan lain sebaginya. Melalui perbedaan ini, kamu memerlukan tempat yang pas agar dianggap sama.Tetap Terhubung, Kamu memiliki koneksi dengan orang-orang dari seluruh dunia dengan hanya menggunakan satu sentuhan atau jempol. Tempat Promosi, Di media sosial, kamu bisa mempromosikan produk atau jasa.Media sosial membuat prosesnya menjadi 
sangat mudah.Contohnya saja, kamu bisa menggunakan Facebook untuk mempromosikan produk.

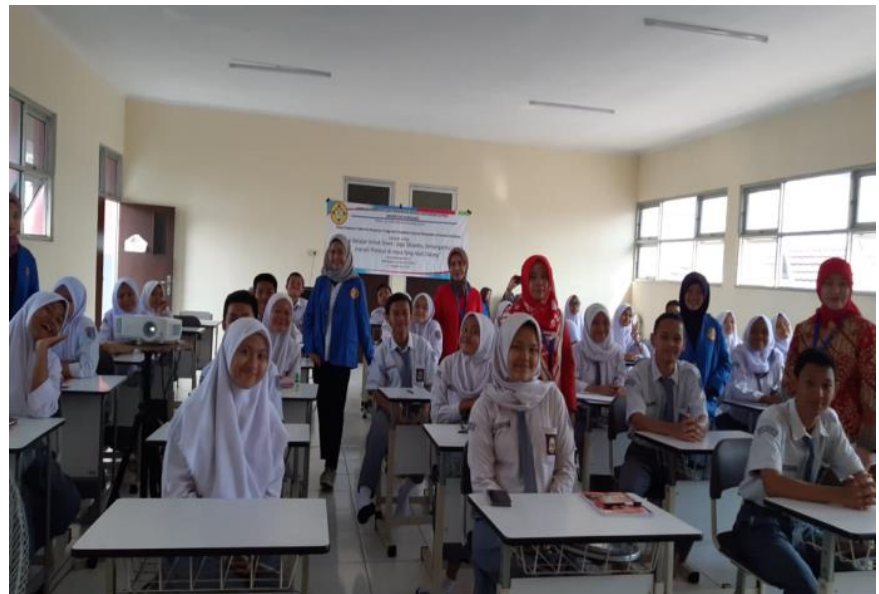

Gambar 2. Kegiatan Sosialisasi PKM terhadap Siswa Siswi Generasi Milenial

Belajar Mandiri, Mengikuti dari seorang ilmuwan atau guru tidak hanya membuat kamu semakin pintar. Tetapi juga membuatmu lebih ahli atau paham apa yang kamu lakukan. Namun di media sosial, kamu bisa mendapatkan tips dan trik, tutorial atau petunjuk, ataupun materi kuliah ada di media sosial. kamu hanya perlu menemukannya atau mencarinya. Menemukan Barang Baru, Semakin banyak kamu mengetahui tentang fitur dan penemuan baru, maka akan semakin cepat kamu menyadari betapa pentingnya inovasi. Ideologi dan Partisipasi Politik, Nilai-nilai patriotik dan nasionalisme telah hilang dan luntur dari generasi muda kita. Apa memang demikian? Kalau kita lihat semangat sepak bola mania di Gelora Bung Karno setiap timnas bertanding malah menunjukkan hal sebaliknya. Juga ketika kita lihat respon mereka di social media ketika simbol-simbol kita dilecehkan negara tetangga, mereka sangat aktif dan gigih membela martabat bangsa dan negaranya.

Generasi Millenials adalah pemilih muda Indonesia.Mereka didominasi oleh swing voters/pemilih galau dan apathetic voters/pemilih cuek. Oleh sebab itu pemerintah harus lebih aktif mensosialisasikan lebih banyak lagi kepada generasi millenials ini tentang dunia politik agar mereka paham dan mau terlibat dalam politik.

Nilai-Nilai Sosial, Social Values, Bagaimana pemuda memaknai arti sebuah keluarga? bagaimana mereka memandang hubungan antara anak dan orang tua? apakah orang tua merupakan role model bagi mereka atau malah mereka lebih memilih role model lain diluar hubungan kekeluargaan?. Ternyata mulai ada pergeseran nilai-nilai sosial ketimuran kita dikalangan pemuda, karena dengan globalisasi, mereka juga dengan mudah mengadopsi nilai-nilai sosial barat yang lebih modern. 


\section{KESIMPULAN DAN SARAN}

Pelaksanaan kegiatan Pengabdian Kepada Masyarakat oleh Lembaga Penelitian dan Pengabdian Masyarakat (LPPM) Universitas Pamulang yang dilakukan oleh dosen-dosen program studi Manajemen telah berjalan dengan lancar dan mendapat sambutan hangat dari tempat pelaksanaan kegiatan ini yaitu SMK Negeri 2 Tangsel, Jl. Mushola Nurul Huda Pamulang Tangerang Selatan.

Dengan pengabdian ini dapat membuka wawasan dari yaitu SMK Negeri 2 Tangsel Dapat menjadi siswa generasi mileial. Materi yang kami berikan yaitu konsep bagaimana menjadi generasi milenial yang kreatif dan mandiri tersebut untuk dapat mengimplementasikannya dalam kehidupan sehari-hari, sehingga dapat membantu dan meningkatkan ekonomi dan keperibadian yang yang akan sangat bermanfaat dalam kehidupan mereka pada masa yang akan datang.

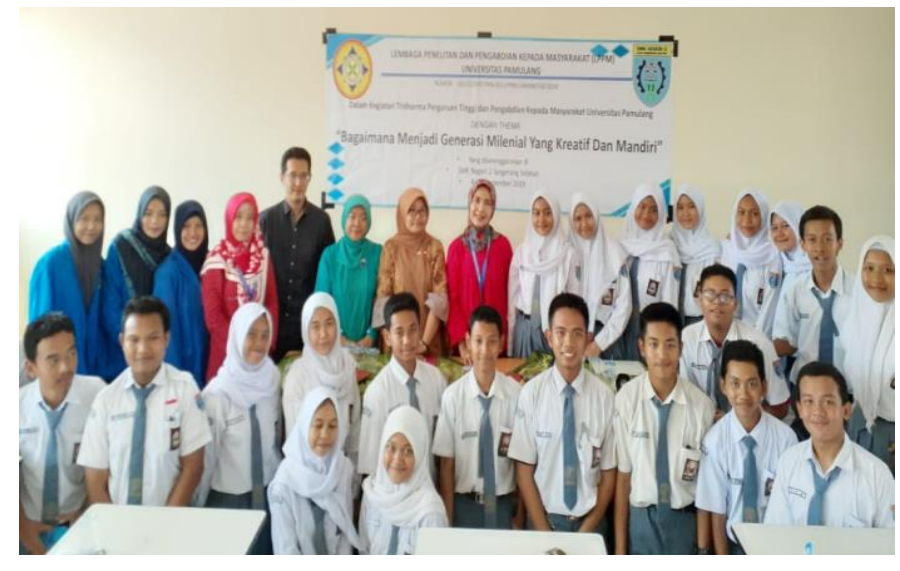

Gambar 3. Foto Bersama dengan Siswa Siswi Milenial

\section{DAFTAR PUSTAKA}

A Sobarna, S Hambali, S Sutiswo, D Sunarsi. (2020). The influence learning used ABC run exercise on the sprint capabilities. Jurnal Konseling dan Pendidikan 8 (2), 67-71

A Sudarsono, D Sunarsi. (2020). Pengaruh Kualitas Pelayanan Dan Varian Produk Terhadap Keputusan Pembelian Pada Laboratorium Klinik Kimia FarmaBintaro. Value: Jurnal Manajemen dan Akuntansi 15 (1), 16-26

Astuti, Ana Puji dan Anike Nurmalita. Teknologi Komunikasi dan Perilaku Remaja.Jurnal Analisa Sosiologi, Vol. 3 No. 1 April 2014

D Sunarsi. (2014). Pengaruh Gaya Kepemimpinan, Motivasi dan Disiplin Kerja Terhadap Kinerja Pendidik. Universitas Pamulang

D Sunarsi. (2014). Pengaruh Gaya Kepemimpinan, Motivasi dan Disiplin Kerja Terhadap Kinerja Pendidik. Universitas Pamulang

Gumilar, I., Sunarsi, D. (2020). Comparison of financial performance in banking with high car and low car (Study of banks approved in the kompas 100 index for the period 2013-2017). International Journal of Psychosocial Rehabilitation. Volume 24 - Issue 7 
Koesoema A, D. 2007. Pendidikan Karakter : Strategi Mendidik Anak di Zaman Global". Jakarta : Grasindo

Maddinsyah, A., Sunarsi, D., Hermawati, R., Pranoto. (2020). Analysis of location selection effect on the user decision that influcence the success of the service business of micro, small and medium enterprise (MSME) in bandung timur region. International Journal of Advanced Science and Technology. Vol. 29 No. 06

Muhari.Pengaruh Penggunaan Teknologi Handphone terhadap Moral Siswa MI Muhammadiyah Gondang Mungkid Magelang. Universitas Islam Indonesia 2018

Panjaitan, Poppy,dan Arik Prasetya. Pengaruh Sosial Media terhadap Produktivitas Kerja Generasi Millenial : Studi pada Karyawan PT. Angkasa Pura I cabang Bandara Internasional Juanda. Jurnal Administrasi Bisnis (JAB)Vol. 48 No. 1 Juli 2017

Purwanti, P., Sarwani, S., \& Sunarsi, D. (2020). Pengaruh Inovasi Produk Dan Brand Awareness Terhadap Keputusan Pembelian Konsumen Pada Pt. Unilever Indonesia. Inovasi, 7(1), 24-31.

Sarwani, S. (2016). Pengaruh Gaya Kepemimpinan dan Strategi Komunikasi Sekda Terhadap Kinerja Pegawai di Sekretariat Daerah Provinsi Kalimantan Selatan. Jurnal Penelitian Pers dan Komunikasi Pembangunan, 19(1).

Sukmadinata, Nana Syaodih. 2012. Metode Penelitian Pendidikan. Bandung : PT Remaja Rosdakarya

Sunarsi, D., \& Asmalah, L. (2018). Pelatihan Manajemen Pengembangan Diri Bagi Penerima Beasiswa RZIS UGM Dan Dompet Shalahuddin Jogjakarta. Jurnal Pengabdian Dharma Laksana, 1(1).

Sunarsi, D., \& Asmalah, L. (2018). Pelatihan Manajemen Pengembangan Diri Bagi Penerima Beasiswa RZIS UGM Dan Dompet Shalahuddin Jogjakarta. Jurnal Pengabdian Dharma Laksana, 1(1), 51-60.

Sunarsi, D., \& Erlangga, A. (2020). The Effect of Leadership Style and Work Environment on the Performance of Stationary Pump Operators in the Water Resources Office of West Jakarta City Administration. International Journal of Advances in Social and Economics, 2(3).

Sunarsi, D., Kustini, E., Lutfi, A. M., Fauzi, R. D., \& Noryani, N. (2019). Penyuluhan Wirausaha Home Industry Untuk Meningkatkan Ekonomi Keluarga Dengan Daur Ulang Barang Bekas. BAKTIMAS: Jurnal Pengabdian pada Masyarakat, 1(4), 188-193.

Sunarsi, D., Kusjono, G., \& Nuryana, I. (2019). Pelatihan Manajemen Penguasaan Kelas Dan Pembuatan Bahan Ajar Bagi Tenaga Pengajar Sukarela Taman Belajar Kreatif Mekarsari. Jurnal Pengabdian Dharma Laksana, 2(1), 41-44. 